\title{
RESEARCH
}

Open Access

\section{Multiple level anterior cervical discectomy and fusion versus posterior laminectomy for the management of multilevel cervical spondylotic myelopathy: clinical and radiological outcome}

\author{
Omar El Farouk Ahmed ${ }^{*}$ (iD and Ahmed Galal
}

\begin{abstract}
Background: Though both anterior and posterior approach are used for the management of multilevel cervical spondylotic myelopathy (CSM), the choice between both approaches remains to be of considerable debate.

Aim of the work: The aim of the study was to evaluate the clinical and radiographic outcomes of patients with multiple level CSM who underwent posterior laminectomy $(\mathrm{PL})$ versus anterior cervical discectomy and fusion (ACDF).

Methods: This is a retrospective comparative study of 30 patients, with multiple level CSM managed by the authors, either by PL $(n=15)$ or ACDF ( $n=15)$. Clinical outcome was assessed at $1,3,6$, and 12 months postoperatively using the modified Japanese Orthopedic Association scale (mJOA) while the postoperative radiographic changes represented by the Cobb's angle variation was recorded at 12 months postoperatively and compared with preoperative values. Also, the incidence of postoperative complications and neurological deterioration was recorded and studied between the two groups. Study duration was for 2 years from December 2014 to December 2016.

Results: Both the ACDF and PL groups showed an improvement in the mJOA score mean value at 1 year after surgery in comparison with the preoperative evaluation data; however, on comparing between both groups at 1 year postoperatively, the median percent of increase in mJOA score was significantly higher in the ACDF group compared with the PL group (33.3\% vs $22.2 \%$ respectively). On the other hand, the Cobb's angle percent of change 1 year after surgery showed a median percent of increase of $18.7 \%$ in the ACDF group in contrast to a median decrease of $-11.1 \%$ in the PL group which was statistically significant. Minimal complications were reported in both groups.
\end{abstract}

Conclusion: Both PL and ACDF are effective modalities for the surgical management of multilevel CSM showing good clinical outcome; however, when compared with the posterior approach, there was a statistical significant difference favoring ACDF regarding the median percent of increase in mJOA score and the postoperative Cobb's angle improvement.

Keywords: Anterior cervical discectomy, Cervical, Laminectomy, Myelopathy

\footnotetext{
* Correspondence: omarelfarouk@hotmail.com

Department of Neurosurgery, Faculty of Medicine, Ain Shams University, Cairo, Egypt
} 


\section{Introduction}

Cervical spondylotic myelopathy (CSM) is a leading cause of spinal cord dysfunction that can substantially decrease quality of life [1]; it may manifests with a variety of findings including difficulty with gait or balance, sphincteric control disturbances, motor weakness, sensory changes, and abnormal reflexes [2, 3]. Imaging of CSM consists of plain radiographs with flexion and extension views to evaluate cervical spine stability, while magnetic resonance imaging (MRI) of the cervical spine remains the most important modality to evaluate the soft tissues about the spine and the spinal cord [3, 4].

The aim of management of cervical spondylotic myelopathy is to provide symptomatic relief and prevention of progressive neurologic dysfunction when the patient's signs and symptoms correlate with the radiographic evidence of cervical canal stenosis (CCS) [1]. Conservative management might be offered for patients with mild myelopathy (that does not interfere with function), whereas severe and progressive cases are candidates for surgical decompression of the spinal cord in the involved segments $[5,6]$.

The choice of surgical procedure and approach to optimize the patients' outcome remains controversial [7]. Many surgeons adopt multiple anterior cervical discectomy and/or corpectomy and fusion as the best choice for treating patients with CCS [8]; other surgeons, however, believe that anterior cervical discectomy and fusion (ACDF) is not the optimal solution for the surgical management of multilevel CSM because of the higher chance of incomplete decompression behind the mid-vertebral body and higher risk of pseudarthrosis due to more graft-host interfaces particularly in the case of multilevel CSM [9]. Anterior approaches, whether discectomy or corpectomy, are mostly used for younger patients, whereas posterior approaches, whether laminectomy or laminoplasty, are frequently offered for older patients with preserved lordosis who are poor candidates for fusion, and except for the risk for intraoperative recurrent laryngeal nerve injury as a distinct complication of the anterior approach, other complications, such as infection and postoperative neurological dysfunction, are relatively comparable $[3,10]$.

The current study compares between multiple level (ACDF) and posterior laminectomy (PL) for the management of CSM as regards the clinical and radiological outcomes as well as the incidence of postoperative complications.

\section{Patients and methods}

This is a retrospective comparative study on 30 patients with multiple level cervical canal stenosis and spondylotic myelopathy, conducted in the period between December 2014 and December 2016.
Thirty patients were enrolled in this study; they were divided according to surgical approach into two groups, the ACDF group (15 patients) and the PL group (15 patients), who were followed up for 12 months after surgery. This study was conducted at Ain Shams university hospitals.

\section{Patient selection \\ Inclusion criteria}

1. Patients with two or three levels cervical canal stenosis between $\mathrm{C} 3$ and $\mathrm{C} 7$ presented with symptoms and signs of myelopathy

2. Radiological results confirming the diagnosis including plain X-ray (PXR) (antero-posterior (A$\mathrm{P})$, lateral views and dynamic views), and magnetic resonance imaging (MRI)

\section{Exclusion criteria}

1. Patients with single level cervical canal stenosis

2. Patients with four or more levels cervical canal stenosis

3. Patients with cervical radiculopathy due to lateral disc herniation or foraminal stenosis

4. Patients with marked cervical instability (i.e., higher than $3 \mathrm{~mm}$ translation)

5. The presence of other cervical spine pathologies such as trauma, tumor, or infection

6. Patients with kyphotic deformity or straightened cervical curve

\section{Preoperative data}

Clinical evaluation

This will include:

1. Patients' demographics (age, sex)

2. Relevant past medical and surgical history

3. Full general and history and neurological examination

4. Clinical presentation and its duration including assessment of the modified Japanese Orthopedic Association (mJOA) score for every patient [11]

\section{Radiological investigation}

Plain radiographs A-P and lateral and dynamic views were obtained to evaluate the anatomy of the cervical spines including evaluation of the facet joints, presence of degenerative changes, neural foraminal dimensions, ossified ligaments, and bone density; in addition to assessment of cervical spine stability and evaluation of preoperative Cobb's angle where the angle between the vertical lines was defined as positive when there was 
lordosis in the cervical spine and negative when there was kyphosis.

MRI Magnetic resonance imaging (MRI) of the cervical spine without gadolinium enhancement allows detailed anatomical evaluation of the spine and spinal cord, nerve roots, and spinal ligaments complex. Focal increased cord signals on T2 images points to demyelination, edema, or cord malacia, and subsequently constitute poorer prognostic findings for patients presented with spondylotic myelopathy.

\section{Surgical techniques \\ ACDF group}

Following general anesthesia and endotracheal intubation, patients were positioned supine with head in neutral position. Skin incision was performed on the right side of the anterior aspect of the neck according to the operated level.

Patients then had microscopic anterior cervical discectomy and decompression of the neural canal and neural foramina; the end plates were carefully cleaned for any residual disc material, and any posterior bony osteophytes were removed using Kerrison rongeurs and/or a drill, then the posterior longitudinal ligament was resected.

All patients included in this group had conventional polyetheretherketone (PEEK) cages (Medtronic); the determination of the implant size was done by cage trials and evaluation through intraoperative lateral radiography with special attention to maximize the end plateimplant contact. The implant was then inserted under slight distraction of the segment using CASPAR vertebral distractors then compression was applied to fixate the implant teeth/serrations of the implant against the bony end plates; none of the patients had cervical plating.

A lateral fluoroscopic image was obtained to ensure safe and proper positioning of the implant.

\section{PL group}

Patients had general anesthesia and endotracheal intubation, then were positioned prone with head in neutral position. A midline skin incision was performed according to the pathological levels. Subperiosteal dissection of the paracervical muscles from the spinous processes and laminae was accomplished; the retractors were intermittently released to avoid denervation of the erector spinae muscles. The laminae was thinned to $1-2 \mathrm{~mm}$ thickness then laminectomy was performed for the residual thickness with a 1 or $2 \mathrm{~mm}$ Kerrison rongeur or the diamond drill; the ligamentum flavum is then visualized and removed.
Finally, closure for both groups was performed in a routine fashion over a suction drain. All patients received prophylactic antibiotics perioperatively and were requested to start ambulation on the next day, if their motor power allows to, using a hard neck collar for a couple of months. The drains were removed at $24 \mathrm{~h}$.

Intraoperative and postoperative data including intraoperative blood loss, operative time, the incidence of postoperative neurological deficit, and the hospital stay were recorded.

All surgeons accounting for performing the two procedures were efficient with the same skill level.

\section{Evaluation follow-up \\ Clinical outcome}

Assessment of the patients' neurological outcome, for the two groups, was through evaluation of the postoperative mJOA scores for all patients at 1, 3, 6, and 12 months postoperatively in comparison to preoperative scores.

\section{Radiological outcome}

Radiological outcome was assessed by plain X-ray (AP, lateral views) on the first postoperative day, then subsequent radiographs were done at land 12 months after surgery.

Radiological evaluation for both groups included the assessment of Cobb's angle and the cervical lordotic curve for both groups.

\section{Statistical analysis}

Continuous variables were tested for normality with Kolmogorov-Smirnov test. Numerical variables were compared between the two study groups using student $t$ test or Mann-Whitney test according to data distribution. Chi-square and Fisher's exact test were used to compare categorical variables. Paired $t$ test and repeated measure analysis of variance (ANOVA) were used to compare means of clinical outcome measurements that is measured twice or several times respectively. A significance level of $P<0.05$ was used in all tests. All statistical procedures were carried out using statistical package for the social sciences (SPSS) version 20 for Windows (SPSS Inc., Chicago, IL, USA).

\section{Results}

All the patients' preoperative data was studied and analyzed. There were 10 (66.7\%) males and 5 (33.3\%) female patients in each group. Their age ranged from 41 to 69 years, with a mean age of $61.8( \pm 6.7 \mathrm{SD})$ years in the PL group and a mean age of $63.4( \pm 6.8 \mathrm{SD})$ years in the ACDF group.

In PL subjects, two level pathology was recorded in 10 $(66.7 \%)$ patients, in contrast to three level pathology in 5 
(33.3\%) patients, while in the ACDF group, they were 8 $(53.3 \%)$ and $7(46.7 \%)$ respectively. In the posterior group, 13 (86.7\%) patients were presented by upper limb weakness while lower limb weakness was noted in 9 $(60 \%)$ patients, similarly, they were recorded in 13 $(86.7 \%)$ and $10(66.7 \%)$ patients in the anterior group respectively.

A positive cord signal in preoperative MRI denoting myelomalacia was positive in $66.7 \%$ of patients in the posterior group versus $40 \%$ of patients in the anterior group with no statistical significance.

There was no statistically significant difference found between both groups regarding the clinical presentation or the demographic data of the studied patients (Table 1).

\section{PL group}

Significant postoperative clinical improvement following laminectomy surgery was noted. Considering mJOA score evaluation, the comparison between the mean values for the preoperative assessment, to those at the third, sixth, and twelfth months postoperatively, showed a statistically highly significant values $(P<0.001)$, while to that at the first postoperative month, the change in mean value was not significant $(P>0.05)$; similarly, a nonsignificant change in the mJOA score mean value was recorded on comparing between the sixth and the twelfth month after surgery; a statistically significant value was also noted on comparing the mean values of the third month to the sixth and twelfth months postoperatively $(P=0.0324$ and $P=0.0331)$ (Table 2).

Table 3 outlines the postoperative change in the mean value of Cobb's angle among the PL group, showing a statistically highly significant difference $(P=0.001)$ between the preoperative and the 1 year postoperative mean values that were recorded $15.58 \pm 4.22$ and $13.42 \pm 4.47$ respectively.

\section{ACDF group}

Similar to the PL group, significant postoperative clinical improvement following the anterior approach was found; on evaluating the mJOA score mean values, the comparison between the preoperative assessment, to those at the third, sixth, and twelfth months postoperatively, showed a statistically highly significant values $(P<$ 0.001 ), while to that at the first postoperative month, the statistical difference in mean value was not significant $(P>0.05)$; also, a statistically significant improvement was noted on comparing the mean values at the first postoperative month to the third, sixth and twelfth months and on comparing between the mJOA score at the third month to the sixth and twelfth months scores $(P<0.001)$. Finally, a nonsignificant change in the mJOA score mean value was recorded on comparing between
Table 1 Demographic and clinical data of the studied patients

\begin{tabular}{|c|c|c|c|c|c|c|}
\hline & \multicolumn{4}{|l|}{ Group } & \multirow[t]{3}{*}{$P$} & \multirow[t]{3}{*}{ Sig. } \\
\hline & \multicolumn{2}{|c|}{ PL Group } & \multicolumn{2}{|c|}{ ACDF Group } & & \\
\hline & Mean & $\pm \mathrm{SD}$ & Mean & $\pm S D$ & & \\
\hline$\overline{\text { Age }}$ & 61.8 & 6.7 & 63.4 & 6.8 & $0.522^{\ddagger}$ & $\overline{N S}$ \\
\hline Disease duration (months) & 7.1 & 4.0 & 6.1 & 4.2 & $0.509^{\ddagger}$ & NS \\
\hline \multicolumn{7}{|l|}{ Sex } \\
\hline Male & 10 & $66.7 \%$ & 10 & $66.7 \%$ & $1.0^{*}$ & NS \\
\hline Female & 5 & $33.3 \%$ & 5 & $33.3 \%$ & & \\
\hline \multicolumn{7}{|l|}{ Number of affected levels } \\
\hline Two & 10 & $66.7 \%$ & 8 & $53.3 \%$ & $0.456^{*}$ & NS \\
\hline Three & 5 & $33.3 \%$ & 7 & $46.7 \%$ & & \\
\hline \multicolumn{7}{|l|}{ Numbness } \\
\hline Negative & 5 & $33.3 \%$ & 3 & $20.0 \%$ & $0.682^{* *}$ & NS \\
\hline Positive & 10 & $66.7 \%$ & 12 & $80.0 \%$ & & \\
\hline \multicolumn{7}{|l|}{ Heaviness } \\
\hline Negative & 2 & $13.3 \%$ & 3 & $20.0 \%$ & $1.0^{* *}$ & NS \\
\hline Positive & 13 & $86.7 \%$ & 12 & $80.0 \%$ & & \\
\hline \multicolumn{7}{|l|}{ Upper limb weakness } \\
\hline Negative & 2 & $13.3 \%$ & 2 & $13.3 \%$ & $1.0^{* *}$ & NS \\
\hline Positive & 13 & $86.7 \%$ & 13 & $86.7 \%$ & & \\
\hline \multicolumn{7}{|l|}{ Lower limb weakness } \\
\hline Negative & 6 & $40.0 \%$ & 5 & $33.3 \%$ & $0.705^{*}$ & NS \\
\hline Positive & 9 & $60.0 \%$ & 10 & $66.7 \%$ & & \\
\hline \multicolumn{7}{|l|}{ Sensory loss } \\
\hline Negative & 2 & $13.3 \%$ & 4 & $26.7 \%$ & $0.651^{* *}$ & NS \\
\hline Positive & 13 & $86.7 \%$ & 11 & $73.3 \%$ & & \\
\hline \multicolumn{7}{|l|}{ Hyperreflexia } \\
\hline Negative & 3 & $20.0 \%$ & 2 & $13.3 \%$ & $1.0^{* *}$ & NS \\
\hline Positive & 12 & $80.0 \%$ & 13 & $86.7 \%$ & & \\
\hline \multicolumn{7}{|l|}{ Babinski } \\
\hline Negative & 6 & $40.0 \%$ & 8 & $53.3 \%$ & $0.464^{*}$ & NS \\
\hline Positive & 9 & $60.0 \%$ & 7 & $46.7 \%$ & & \\
\hline \multicolumn{7}{|l|}{ Hoffmann } \\
\hline Negative & 6 & $40.0 \%$ & 11 & $73.3 \%$ & $0.065^{*}$ & NS \\
\hline Positive & 9 & $60.0 \%$ & 4 & $26.7 \%$ & & \\
\hline \multicolumn{7}{|l|}{ Ankle clonus } \\
\hline Negative & 11 & $73.3 \%$ & 11 & $73.3 \%$ & $1.0^{* *}$ & NS \\
\hline Positive & 4 & $26.7 \%$ & 4 & $26.7 \%$ & & \\
\hline \multicolumn{7}{|l|}{ Cord signal } \\
\hline Negative & 5 & $33.3 \%$ & 9 & $60.0 \%$ & $0.143^{*}$ & NS \\
\hline Positive & 10 & $66.7 \%$ & 6 & $40.0 \%$ & & \\
\hline \multicolumn{7}{|l|}{ Sphincteric disturbance } \\
\hline Negative & 9 & $60.0 \%$ & 8 & $53.3 \%$ & $0.713^{*}$ & NS \\
\hline Positive & 6 & $40.0 \%$ & 7 & $46.7 \%$ & & \\
\hline
\end{tabular}

$P L$ posterior laminectomy, $A C D F$ anterior cervical discectomy and fusion, $S D$ standard deviation, NS nonsignificant

${ }^{\text {F}}$ Student $t$ test

*chi-square tests

**Fisher exact test 
Table 2 Comparison between preoperative and postoperative mJOA score mean values at different follow-up intervals among PL group

\begin{tabular}{lll}
\hline & Mean & $\pm \mathrm{SD}$ \\
\hline mJOA pre & 11.3 & 2.2 \\
mJOA post 1 month & 11.7 & 2.8 \\
mJOA post 3 months & 13.1 & 3.3 \\
mJOA post 6 months & 13.7 & 3.7 \\
mJOA post 12 months & 13.6 & 3.6 \\
\hline
\end{tabular}

mJOA modified Japanese Association score, SD standard deviation, NS

nonsignificant, $S$ significant, $H S$ highly significant

the sixth and the twelfth month after surgery $(P>$ 0.05)(Table 4).

Table 5 describes the postoperative change in the mean value of Cobb's angle, showing a statistically highly significant difference $(P=0.007)$ between the preoperative and the 1 year postoperative mean values, that were recorded $12.68 \pm 3.55$ and $14.66 \pm 4.06$ respectively.

Five of 15 patients (33.3\%) in the ACDF group experienced cage non-union; out of these 5 patients, 3 had 3 levels ACDF, and 2 had 2 levels ACDF; all, however, were asymptomatic and required no revision surgery; cage subsidence was recorded in 3 out of 15 patients, as of 7 of 37 operated levels (18.9\%) in the anterior group; also, no affection of the clinical outcome was noted.

Table 6 states that on comparing between the PL and the ACDF groups regarding the preoperative and the postoperative mJOA score mean values there were no statistically significant differences $(P>0.05)$ (Fig. 1). Also, there were no statistically significant difference on comparing between Cobb's angle mean values preoperatively and at 1 year after surgery $(P>0.05)$ (Fig. 2).

However, there was a statistically significant difference regarding the median percent of increase in mJOA score mean values after surgery $(P=0.03)$ being significantly higher in the ACDF group compared with the PL group (33.3\% vs $22.2 \%)$ (Fig. 3). Also, there was a statistically highly significant difference regarding Cobb's angle percent of change after intervention $(P=0.001)$, showing a median percent of increase of $18.7 \%$ in the ACDF group in contrast to a median decrease of $-11.1 \%$ in the laminectomy group (Fig. 4) (Table 7).

Unintended durotomy was encountered in a single patient in the PL group; the dural tear was sutured intraoperatively and augmented by a fat graft; drain was kept

Table 3 Comparison between preoperative and postoperative Cobb's angle mean values among the ACDF group

\begin{tabular}{lllll}
\hline & Mean & \pm SD & $P$ & Sig. \\
\hline Cobb's angle Pre & 15.58 & 4.22 & 0.001 & HS \\
Cobb's angle Post 1 year & 13.42 & 4.47 & & \\
\hline
\end{tabular}

SD standard deviation, $H S$ highly significant
Table 4 Comparison between preoperative and postoperative mJOA score mean values at different follow-up intervals among ACDF group

\begin{tabular}{lll}
\hline & Mean & $\pm \mathrm{SD}$ \\
\hline mJOA Pre & 10.8 & 1.4 \\
mJOA post 1 month & 10.3 & 2.0 \\
mJOA post 3 month & 12.8 & 2.9 \\
mJOA post 6 month & 13.6 & 3.2 \\
mJOA Post 12 month & 13.7 & 3.3 \\
\hline
\end{tabular}

mJOA modified Japanese Association score, SD standard deviation, NS nonsignificant, $H S$ highly significant

in a nondependant location with no suction then a stitch was taken at its place when removed; no subsequent collection or leakage was recorded.

A single patient of the ACDF developed temporary recurrent laryngeal nerve injury on the same side of operation immediately after surgery; he received conservative medical management and had complete recovery within 1 month; another patient of the PL group developed immediate postoperative C5 palsy; severe deltoid paresis (motor Grade 2/5) was noted with no intraoperative findings to explain the event; accordingly, patient started rehabilitation program and had full recovery of deltoid function by the sixth postoperative month. One patient of each group had postoperative superficial wound infection that was successfully cured in less than 2 weeks using oral antibiotics and frequent wound dressings.

There was no statistically significant difference between both groups concerning operative time, intraoperative blood loss, and length of hospital stay despite of showing shorter mean operative time and lesser intraoperative blood loss in the ACDF group.

There was no statistically significant difference regarding the postoperative complications between the PL group and the ACDF group (Table 8).

\section{Discussion}

Over the last years, the decision making regarding the surgical management of CSM had been reviewed through several studies [12, 13], as the selection of the surgical approach for the treatment of multilevel CSM remains controversial. While PL, as a wellestablished procedure, has gained its widespread acceptance in the surgical management of multilevel cervical myelopathy through indirect decompression

Table 5 Comparison between preoperative and postoperative Cobb's angle mean values among the ACDF group

\begin{tabular}{lll}
\hline & Mean & \pm SD \\
\hline Cobb's angle Pre & 12.68 & 3.55 \\
Cobb's angle at 1 year post & 14.66 & 4.06 \\
\hline
\end{tabular}

SD standard deviation, $H S$ highly significant 
Table 6 Comparison between preoperative and postoperative mJOA scores and Cobb's angle mean values in both groups

\begin{tabular}{|c|c|c|c|c|}
\hline & \multicolumn{4}{|l|}{ Group } \\
\hline & \multicolumn{2}{|c|}{$\mathrm{PL}$ group } & \multicolumn{2}{|c|}{ ACDF group } \\
\hline & $\overline{\text { Mean }}$ & $\pm \mathrm{SD}$ & Mean & $\pm \mathrm{SD}$ \\
\hline mJOA Pre & 11.33 & 2.16 & 10.80 & 1.42 \\
\hline mJOA post 1 month & 11.73 & 2.81 & 10.33 & 2.02 \\
\hline mJOA post 3 month & 13.13 & 3.31 & 12.80 & 2.86 \\
\hline mJOA post 6 month & 13.67 & 3.70 & 13.60 & 3.25 \\
\hline mJOA Post 12 month & 13.60 & 3.66 & 13.73 & 3.35 \\
\hline Cobb's angle Pre & 15.58 & 4.23 & 12.69 & 3.55 \\
\hline Cobb's angle Post 1 year & 13.42 & 4.48 & 14.66 & 4.07 \\
\hline
\end{tabular}

SD standard deviation, NS nonsignificant

of the anterior aspect of the spinal cord via posterior spinal cord shift; also, ACDF is an effective modality for direct neural decompression aiming at correcting cervical kyphotic alignment and preserving the stability of the cervical spine [14].

The current study was conducted to evaluate the clinical and radiographic outcomes of patients with multiple level cervical spondylotic myelopathy who underwent anterior cervical discectomy and fusion (ACDF) in comparison with posterior laminectomy (PL). Cunningham et al. [12] discussed surgical treatment for CSM through a systemic review of cohort studies where they focused on comparing the clinical outcomes using anterior and posterior approaches (ACDF, corpectomy, laminectomy, and laminoplasty). They concluded that all anterior and posterior approaches yielded similar neurological recovery rates and suggested that the decision making in the management of multi-segmental CSM is in fact challenging for treating physicians. Liu et al. [13] also published a systemic review on different approaches (anterior and posterior) for the treatment of multilevel myelopathy, including cases associated with cervical spondylosis and ossification of the posterior longitudinal ligament (OPLL); they stated that for multilevel CSM patients, the final follow-up JOA score for the anterior group was significantly higher than the posterior group in the "follow-up time $\leq 5$ years" subgroup, yet had no significant differences in the "follow-up time $>5$ years" subgroup.

Ghogawala et al. [15] performed a study to assess the eligibility for randomization to surgical approaches in the management of CSM, the authors sent the radiographic images of 20 cases to 239 surgeons and asked them to state their preferred surgical approach and the possible eligibility for randomization. Out of the 20 cases, 12 were evaluated as potentially eligible for randomization.

According to our current study, significant postoperative clinical improvement was noted following both approaches; considering mJOA score evaluation, the postoperative mean values of both groups in comparison with the preoperative assessment showed a significant improvement; but both groups showed a nonsignificant improvement during the first postoperative months and between the 6th and 12 months after surgery; eventually, there was a statistically significant difference regarding the median percent of increase in mJOA score mean values after surgery $(P=0.03)$ being significantly higher in the ACDF group(33\%) compared with the PL group (22.2\%). However, it is important to note that the

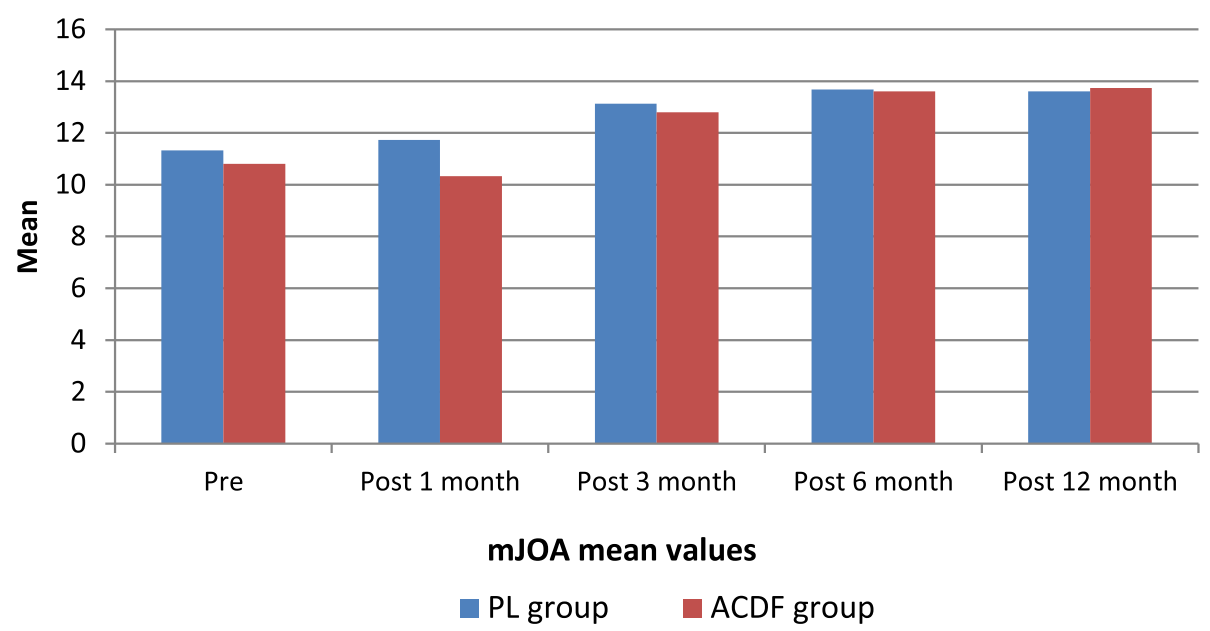

Fig. 1 mJOA score mean value preoperatively and at 1, 3, 6, and 12 months postoperatively for both PL and ACDF groups 


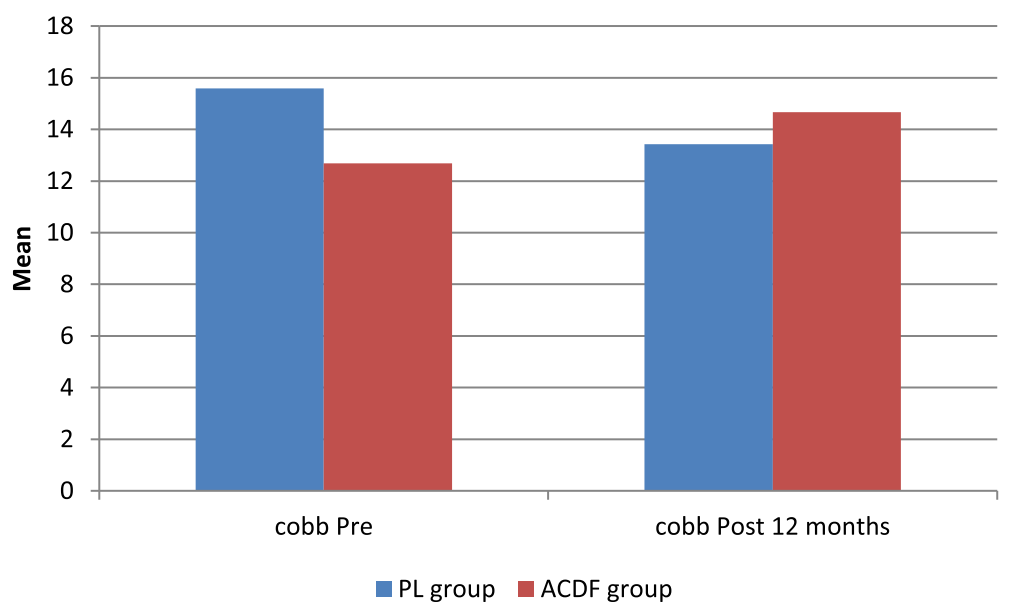

Fig. 2 Cobb's angle mean value preoperatively and at 12 months postoperatively for both groups

preoperative radiological higher incidence of cord signal among the PL group in comparison with the ACDF group ( $66.7 \%$ and $40 \%$ respectively) might be a contributing factor to provide an explanation for this difference.

Zhu et al. [16] selected two clinical outcome end points in their meta-analysis; they found no statistically significant difference between the anterior group and the posterior group on comparing the preoperative JOA scores; however, the postoperative JOA scores were better in the anterior group compared with the posterior surgery group. These findings suggested that the two groups had similar baseline neural function, whereas the postoperative neural function improvement was better in the anterior surgery group in comparison with the posterior surgery group. According to Wang et al. [17] study, all patients recorded similar clinical improvements as evaluated by the JOA scores after surgery with no significant difference between anterior or posterior approaches. Hirai et al. [18] suggested that the residual anterior compression of the spinal cord after posterior decompression was the cause of the lower recovery rate in the posterior surgery group, interestingly, the recovery rate between both groups was similar without residual anterior compression.

In accordance with our current study, several reports indicate satisfactory clinical outcomes with ACDF using stand-alone cages for the treatment of multilevel CSM [19]. One of the concerns in multilevel ACDF using stand-alone cages includes risks for non-union and cage subsidence. Zhou et al. [20] described in their study that 13 out of the 15 studied patients achieved a solid fusion, following an average postoperative time of 5.7 months, while the radiographic fusion rate was $93.3 \%$. In the current study, 5 of 15 patients (33.3\%) in the ACDF group experienced non-union; however, all were asymptomatic and required no revision surgery. In our current study,

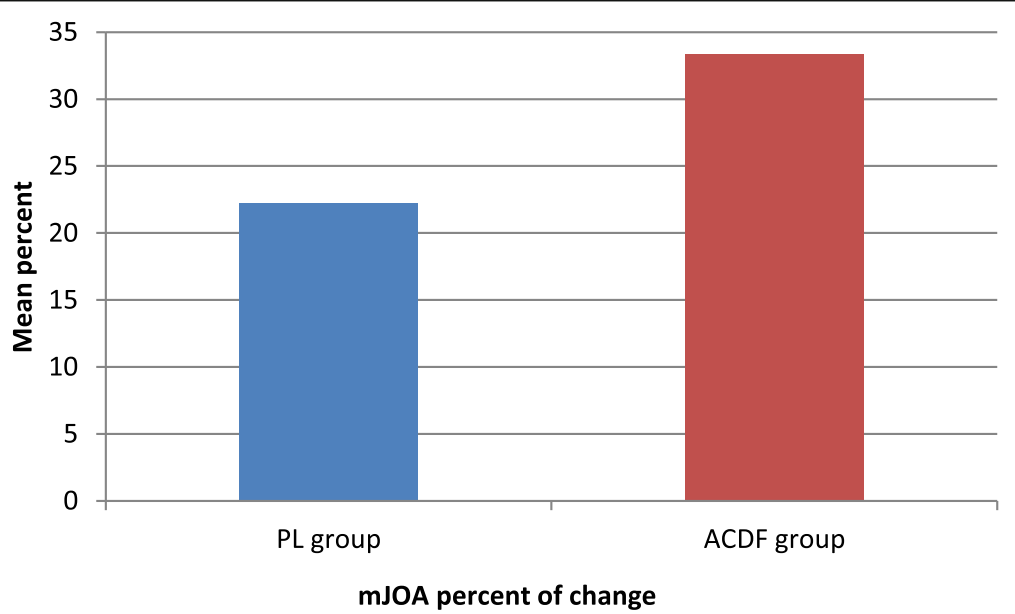

Fig. $3 \mathrm{mJOA}$ score percent of change in mean values following surgery in both groups 


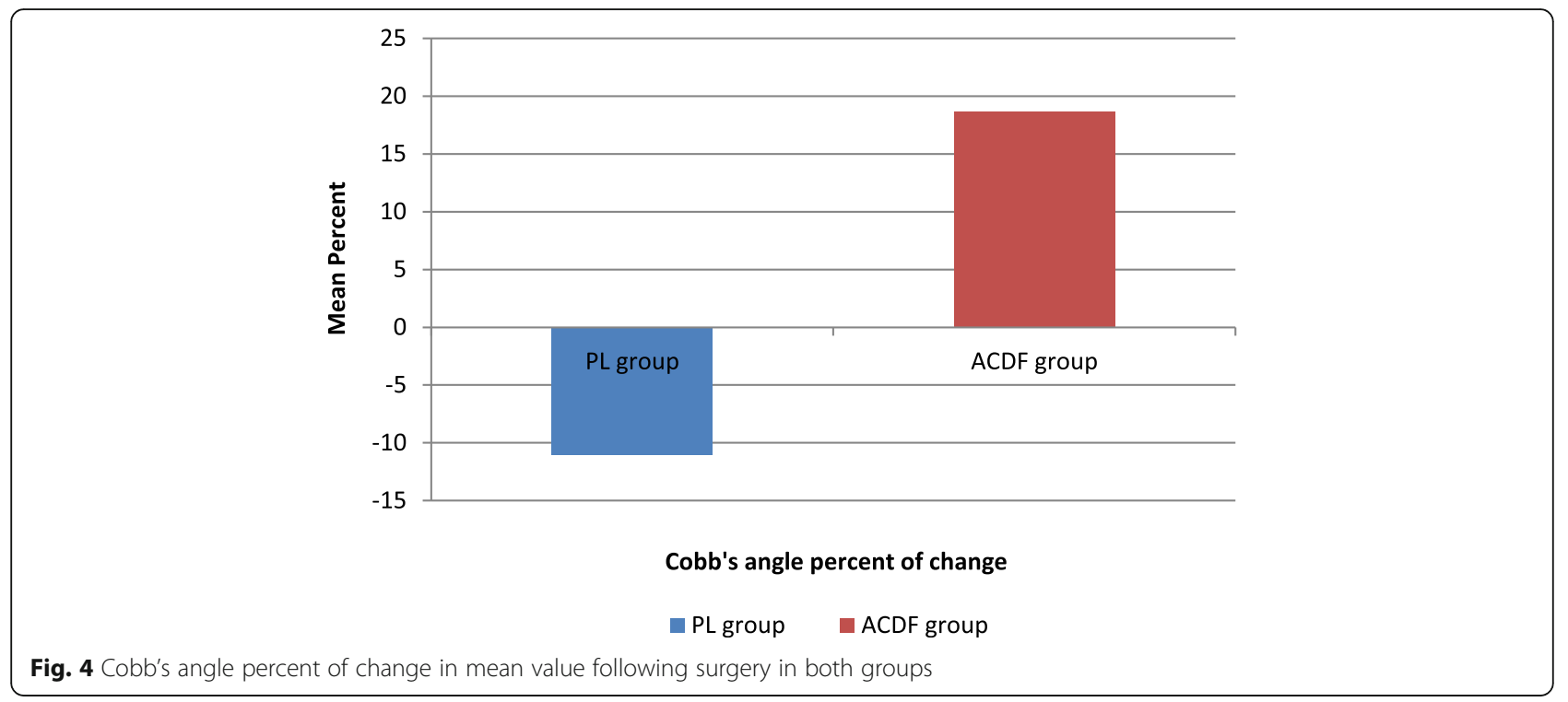

subsidence was recorded in 3 out of 15 patients, as of 7 of 37 operated levels (18.9\%) in the ACDF group, none of them were clinically affected. Zajonz et al. [21] reviewed 18 studies of ACDF involving 1468 cases and concluded that clinical outcomes were unaffected by subsidence.

Considering Cobb's angle changes, our study revealed a statistically highly significant difference between the preoperative and the 1 year postoperative mean values for both groups, the PL group recorded $15.58 \pm 4.22$ and $13.42 \pm 4.47$ respectively; whereas the ACDF group recorded $12.68 \pm 3.55$ and $14.66 \pm 4.06$ respectively. However, there was a statistically highly significant difference regarding Cobb's angle percent of change 1 year postoperatively showing a median percent of increase of $18.7 \%$ in the ACDF group in contrast to a median decrease of $-11.1 \%$ in the laminectomy group suggesting that ACDF was more efficacious at restoring cervical disc height and cervical curvature.

Wang et al. [17] described that cervical lordosis significantly improved at 1 week postoperatively in all patients in both anterior and posterior groups; these improvements in cervical lordosis were more obvious in patients of the anterior group compared with the posterior group. Surprisingly, the loss of cervical lordosis at the final follow-up of 2 years was significantly more pronounced in patients who had ACDF using a stand-alone cage $\left(11.7 \pm 2.2^{\circ}\right)$.

The postoperative lordotic changes according to Lee et al. [22] were $5.85^{\circ}$ after ACDF with the use of anterior cervical plating. They proposed that the clinical outcomes were not affected by the loss of cervical lordosis after ACDF. Another biomechanical study by Patwardhan et al. showed that cervical sagittal mal-alignment may play a role in aggravating adjacent segment degeneration after multilevel fusion considering the increasing mechanical burden on the adjacent segment [23].

Zhu et al. [16] found a statistically significantly higher incidence of complications with the anterior approach group for the treatment of multilevel CSM compared with the posterior surgery group. Considering most of the complications were pseudarthrosis or the reoperation rate. Cunningham et al. [12] stated that incidence of complications increased significantly with the number of involved anterior surgical segments.

Our study found no statistically significant difference between the anterior and the posterior groups concerning operative time, intraoperative blood loss, and length of hospital stay despite of showing shorter mean operative

Table 7 Comparison between preoperative and postoperative mJOA scores and Cobb's angle mean values in both groups

\begin{tabular}{|c|c|c|c|c|c|c|c|c|c|c|c|c|}
\hline & \multicolumn{10}{|l|}{ Group } & \multirow[t]{3}{*}{$P$} & \multirow[t]{3}{*}{ Sig } \\
\hline & \multicolumn{5}{|c|}{ PL Group } & \multicolumn{5}{|c|}{ ACDF Group } & & \\
\hline & Mean & $\pm \mathrm{SD}$ & Median & IQR & & Mean & $\pm \mathrm{SD}$ & Median & IQR & & & \\
\hline mJOA percent of change & 19.4 & 20.1 & 22.2 & 14.3 & 27.3 & 27.0 & 28.0 & 33.3 & 30.0 & 45.5 & 0.03 & $\mathrm{~S}$ \\
\hline Cobb's angle percent of change & -14.9 & 15.7 & -11.1 & -23.1 & -2.6 & 17.9 & 23.2 & 18.7 & 11.9 & 33.3 & 0.001 & HS \\
\hline
\end{tabular}

$S D$ standard deviation, $S$ significant, $H S$ highly significant, $I Q R$ Interquartile range Mann-Whitney test 
Table 8 Perioperative data and operative complications

\begin{tabular}{|c|c|c|c|c|c|c|}
\hline & \multicolumn{4}{|l|}{ Group } & \multirow[t]{3}{*}{$P$} & \multirow[t]{3}{*}{ Sig. } \\
\hline & \multicolumn{2}{|l|}{$\mathrm{PL}$} & \multicolumn{2}{|l|}{ ACDF } & & \\
\hline & Mean & $\pm S D$ & Mean & $\pm S D$ & & \\
\hline Operative time (min) & 90.67 & 19.81 & 87.77 & 17.41 & 0.443 & NS \\
\hline Intraoperative blood loss (ml) & 115.33 & 25.46 & 105.07 & 22.95 & 0.439 & NS \\
\hline Hospital stay (days) & 2.00 & 1.07 & 2.00 & 1.07 & 1.0 & NS \\
\hline \multicolumn{7}{|l|}{ Recurrent laryngeal N. injury } \\
\hline No & 15 & $100.0 \%$ & 14 & $93.3 \%$ & 1.0 & NS \\
\hline Yes & 0 & $0 \%$ & 1 & $6.7 \%$ & & \\
\hline \multicolumn{7}{|l|}{ Dural tear } \\
\hline No & 14 & $93.3 \%$ & 15 & $100.0 \%$ & 1.0 & NS \\
\hline Yes & 1 & $6.7 \%$ & 0 & $.0 \%$ & & \\
\hline \multicolumn{7}{|l|}{ Superficial wound Infection } \\
\hline No & 14 & $93.3 \%$ & 14 & $93.3 \%$ & 1.0 & NS \\
\hline Yes & 1 & $6.7 \%$ & 1 & $6.7 \%$ & & \\
\hline \multicolumn{7}{|l|}{ C5 palsy } \\
\hline No & 14 & $93.3 \%$ & 15 & $100.0 \%$ & 1.0 & NS \\
\hline Yes & 1 & $6.7 \%$ & 0 & $.0 \%$ & & \\
\hline
\end{tabular}

SD standard deviation, NS nonsignificant

time and lesser intraoperative blood loss in the ACDF group. Similarly, Wang et al. [17] noted that ACDF using a stand-alone cage was associated with significantly less blood loss compared with a posterior approach, while operative time was similar for both procedures.

A previous study shows that C5 nerve root palsy is more likely to happen in patients who undergo posterior decompression compared with ACDF following excessive spinal cord drift after laminectomy [24]; postoperative C5 palsy may also associate the presence of C4-5 high intensity cord signal changes or a long duration of symptoms [25]. In the meta-analysis by Shou et al. [26], the highest prevalence of $\mathrm{C} 5$ palsy was noted among the patients who had laminectomy and fusion (11.0\%), in contrast to (3.3\%) in the ACDF group. The prevalence of C5 palsy according to Wang et al. [17] study was $6.25 \%$ in the posterior laminectomy and fusion group $(2 / 32 \mathrm{pa}-$ tients). In our study, a single patient of the PL group 6.67\% (1/15) developed immediate postoperative C5 palsy; patient was presented by severe deltoid paresis (motor Grade 2/5), yet there was no intraoperative findings to explain the event, patient then started his rehabilitation program and had full recovery of deltoid function 6 months after the operation.

Finally, long-term adverse effects would require further studies and considerations, such as the long-term incidence of adjacent segment degeneration and loss of corrected cervical lordosis following multilevel ACDF using a stand-alone cage, as well as the incidence of neurological deterioration following both approaches.

\section{Conclusion}

Both PL and ACDF are effective modalities for the surgical management of multilevel CSM showing good clinical outcome and postoperative neural function improvement; however, when compared with the posterior approach, there was a statistically significant difference favoring ACDF regarding the median percent of increase in mJOA score and the postoperative Cobb's angle improvement. Further randomized controlled trials and long-term evaluation would be necessary to demonstrate the impact of these findings.

\section{Abbreviations}

ACDF: Anterior cervical discectomy and fusion; ANOVA: Analysis of variance; A-P: Antero-posterior; CCS: Cervical canal stenosis; CSM: Cervical spondylotic myelopathy; HS: Highly significant; IQR: Interquartile range; mJOA: The modified Japanese Orthopedic Association; MRI: Magnetic resonance imaging; NS: Nonsignificant; OPLL: Ossification of the posterior longitudinal ligament; PEEK: Polyetheretherketone; PL: Posterior laminectomy; PXR: Plain X-ray; S: Significant; SD: Standard deviation; SPSS: Statistical package for the social sciences

\section{Acknowledgements}

Not applicable

\section{Authors' contributions}

O.E was the main author and corresponding author. A.G was the co-author. The study design, execution and follow-up of the clinical cases, data analysis and results formulation, and writing of the manuscript were all the joint work of all the authors. Both authors read and approved the final manuscript.

\section{Funding}

The authors received no external funding for the design of the study, for the collection, analysis and interpretation of data or for writing the manuscript. 


\section{Availability of data and materials}

All the raw data and results of the statistical analysis are available with the authors and ready to be shared with authorized personnel upon request; however, for reasons of patency protection it was not submitted with the manuscript.

\section{Ethics approval and consent to participate}

This research was conducted upon obtaining the approval of the ethical committee of the Faculty of Medicine-Ain Shams University, in January 2016. Since this study involved human subjects, an informed consent was signed and acquired from all the participants or their legal guardians in accordance with the ethical committee recommendations.

\section{Consent for publication}

Not applicable. This work was entirely carried out by the authors without any external contributions.

\section{Competing interests}

The authors declare that they have no competing interests.

Received: 13 September 2019 Accepted: 7 February 2020

Published online: 27 February 2020

\section{References}

1. Hassen KM, Mohammadein A. Laminoplasty versus multiple anterior cervical discectomy for cervical spondylotic myelopathy in patients with a lordotic cervical spine. Egypt Orthop J. 2013:48(4):369-75

2. Rao RD, Currier BL, Albert TJ, Bono CM, Marawar SV, Poelstra KA, et al. Degenerative cervical spondylosis: clinical syndromes, pathogenesis, and management. J Bone Joint Surg Am. 2007;89(6):1360-78.

3. Yalamanchili K, Vives M, Chaudhary S. Cervical spondylotic myelopathy: factors in choosing the surgical approach. Adv Orthop. 2012;783762.

4. Teresi LM, Lufkin RB, Reicher MA, Moffit BJ, Vinuela FV, Wilson GM, et al. Asymptomatic degenerative disk disease and spondylosis of the cervical spine: MR imaging. Radiology. 1987;164(1):83-8.

5. Matsumoto M, Chiba K, Ishikawa M, Maruiwa H, Fujimura $Y$, Toyama $Y$. Relationships between outcomes of conservative treatment and magnetic resonance imaging findings in patients with mild cervical myelopathy caused by soft disc herniations. Spine (Phila Pa 1976). 2001;26(14):1592-8.

6. Matz PG, Holly LT, Mummaneni PV, Anderson PA, Groff MW, Heary RF, et al. Anterior cervical surgery for the treatment of cervical degenerative myelopathy. J Neurosurg Spine. 2009;11(2):170-3.

7. Geck J, Eismont F. Surgical options for the treatment of cervical spondylotic myelopathy. Orthop Clin North Am. 2002;33(2):329-48.

8. Hirabayashi K, Bohlman H. Multilevel cervical spondylosis. Laminoplasty versus anterior decompression. Spine (Phila Pa 1976). 1995;20(15):1732-4.

9. Fountas KN, Kapsalaki EZ, Nikolakakos LG, Smisson HF, Johnston KW, Grigorian AA, et al. Anterior cervical discectomy and fusion associated complications. Spine (Phila Pa 1976). 2007;32(21):2310-7.

10. Fehlings MG, Barry S, Kopjar B, Yoon ST, Arnold P, Massicotte EM, et al. Anterior versus posterior surgical approaches to treat cervical spondylotic myelopathy: outcomes of the prospective multicenter AOSpine North America CSM study in 264 patients. Spine (Phila Pa 1976). 2013;38(26):2247-52.

11. Benzel EC, Lancon J, Kesterson L, Hadden T. Cervical laminectomy and dentate ligament section for cervical spondylotic myelopathy. J Spinal Disord. 1991;4(3):286-95.

12. Cunningham MR, Hershman S, Bendo J. Systematic review of cohort studies comparing surgical treatments for cervical spondylotic myelopathy. Spine (Phila Pa 1976). 2010;35(5):537-43.

13. Liu T, Xu W, Cheng T, Yang HL. Anterior versus posterior surgery for multilevel cervical myelopathy, which one is better? A systematic review. Eur Spine J. 2011;20(2):224-35.

14. Seng C, Tow B, Siddiqui M, Srivastava A, Wang L, Yew A, et al. Surgically treated cervical myelopathy: a functional outcome comparison study between multilevel anterior cervical decompression fusion with instrumentation and posterior laminoplasty. Spine J. 2013;13(7):723-31.

15. Ghogawala Z, Coumans JV, Benzel EC, Stabile LM, Barker FG 2nd. Ventral versus dorsal decompression for cervical spondylotic myelopathy: surgeons' assessment of eligibility for randomization in a proposed randomized controlled trial: results of a survey of the Cervical Spine Research Society. Spine (Phila Pa 1976). 2007;32(4):429-36.
16. Zhu B, Xu Y, Liu X, Liu Z, Dang G. Anterior approach versus posterior approach for the treatment of multilevel cervical spondylotic myelopathy: a systemic review and meta-analysis. Eur Spine J. 2013;22(7):1583-93.

17. Wang B, Lü G, Kuang L. Anterior cervical discectomy and fusion with standalone anchored cages versus posterior laminectomy and fusion for fourlevel cervical spondylotic myelopathy: a retrospective study with 2-year follow-up. BMC Musculoskelet Disord. 2018;19(1):216.

18. Hirai T, Okawa A, Arai Y, Takahashi M, Kawabata S, Kato T, et al. Middle-term results of a prospective comparative study of anterior decompression with fusion and posterior decompression with laminoplasty for the treatment of cervical spondylotic myelopathy. Spine (Phila Pa 1976). 2011;36(23):1940-7.

19. Chen Y, Lü G, Wang B, Li L, Kuang L. A comparison of anterior cervical discectomy and fusion (ACDF) using self-locking stand-alone polyetheretherketone (PEEK) cage with ACDF using cage and plate in the treatment of three-level cervical degenerative spondylopathy: a retrospective study with 2-year follow-up. Eur Spine J. 2016;25(7):2255-62.

20. Zhou J, Li X, Dong J, Zhou X, Fang T, Lin H, et al. Three-level anterior cervical discectomy and fusion with self-locking stand-alone polyetheretherketone cages. J Clin Neurosci. 2011;18(11):1505-9.

21. Zajonz D, Franke AC, von der Höh N, Voelker A, Moche M, Gulow J, et al. Is the radiographic subsidence of stand-alone cages associated with adverse clinical outcomes after cervical spine fusion? An observational cohort study with 2-year follow-up outcome scoring. Patient Saf Surg. 2014;8(1):43.

22. Lee J, Park M, Moon S, Shin J, Kim S, Kim Y, et al. Loss of lordosis and clinical outcomes after anterior cervical fusion with dynamic rotational plates. Yonsei Med J. 2013;54(3):726-31.

23. Patwardhan A, Khayatzadeh S, Nguyen N, Havey R, Voronov L, Muriuki M, et al. Is cervical sagittal imbalance a risk factor for adjacent segment pathomechanics after multilevel fusion? Spine (Phila Pa 1976). 2016;41(10): E580-8.

24. Gu Y, Cao P, Gao R, Tian Y, Liang L, Wang C, et al. Incidence and risk factors of C5 palsy following posterior cervical decompression: a systematic review. PLoS One. 2014;9(8):e101933.

25. Liu G, Reyes M, Riew K. Why does C5 palsy occur after prophylactic bilateral C4-5 foraminotomy in open-door cervical laminoplasty? A risk factor analysis. Global Spine J. 2017;7(7):696-702.

26. Shou F, Li Z, Wang H, Yan C, Liu Q, Xiao C. Prevalence of C5 nerve root palsy after cervical decompressive surgery: a meta-analysis. Eur Spine J. 2015;24(12):2724-34.

\section{Publisher's Note}

Springer Nature remains neutral with regard to jurisdictional claims in published maps and institutional affiliations.

\section{Submit your manuscript to a SpringerOpen ${ }^{\circ}$ journal and benefit from:}

- Convenient online submission

- Rigorous peer review

- Open access: articles freely available online

- High visibility within the field

- Retaining the copyright to your article

Submit your next manuscript at $>$ springeropen.com 